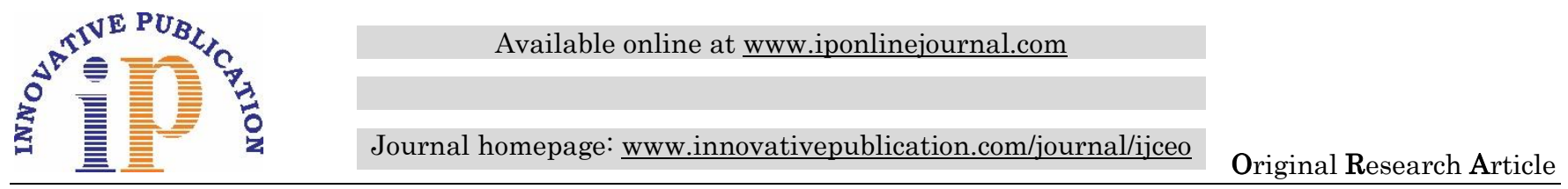

\title{
Comparison of central macular thickness by optical coherence tomography (OCT) in normal and diabetic patients without diabetic retinopathy
}

\author{
Archana Tadwalkar ${ }^{1}$, Sumita Karandikar ${ }^{2 *}$, Pooja Sharma ${ }^{3}$ \\ ${ }^{\mathbf{1}}$ Assistant Professor, ${ }^{2}$ Associate Professor, ${ }^{3}$ Junior Resident, Dept. of Ophthalmology, DY. Patil Medical College, Mumbai, Maharashtra, \\ India
}

\section{Article Info}

Received: $19^{\text {th }}$ February, 2019

Accepted: $5^{\text {th }}$ April, 2019

Published Online: $9^{\text {th }}$ September, 2019

Keywords: OCT, Diabetic retinopathy.

\begin{abstract}
Optical coherence tomography provides a high-resolution imaging of ocular tissues to improve the diagnosis and management of diabetic retinopathy by producing reliable, reproducible and objective retinal images especially in diabetic macular edema that can clearly only be detected with OCT. It enhances the ability to exactly diagnose diabetic macular edema, epiretinal membranes, vitreomacular or vitroretinal traction. OCT also helps in visualising morphological changes of the retina in diabetic retinopathy. It demonstrates that macular edema which is a complex clinical entity with various morphology. With the OCT, structural changes and quantitative assessment of macular edema have become feasible as determined with retinal thickness and volume.
\end{abstract}

\section{Introduction}

There is vast increase in patients of diabetes across the world according to WHO (World Health Organization). The number of diabetics will increase from more than 422 million persons to 552 million expected number in the year 2030. ${ }^{3,4}$ Most commonly found ocular complication in diabetics is Diabetic retinopathy (DR) which ultimately leads to blindness. Therefore, for screening work and early diagnosis \& treatment few objective \& reproducible tests are needed for proper assessment of diabetic retinopathy, \& to record any macular thickness \& other significant changes in them.

The most common and important sign in diabetic retinopathy patients is Macular oedema which leads to blindness in near future. Therefore, there is a need of early diagnosis of such condition, thereby the disease can be avoided. ${ }^{6}$ The metabolic control \& start of medical treatment can reduce the complications of disease \& also play a vital role in post-ponement of potential visual compromise. There is high incidence of macular oedema \& it is evident in $10 \%$ of diabetics. Diabetic retinopathy is commonly seen in type 2 diabetes mellitus in comparison to type 1 diabetes mellitus. ${ }^{7}$

New studies have shown that neurological degeneration imparts vital role in the pathogenesis of diabeticretinopathy. ${ }^{8}$ Regulation of blood flow \& neural activity have significant interaction and is considered to be involved in the patho-physiologic mechanism of diabetic retinopathy, $\&$ is considered as neurovascular coupling. ${ }^{9,10}$

Optical coherence tomography (OCT) is required for quantitative analysis of retinal architecture \& gives detailed scans of retinal structure with a high resolution, retinal thickness, choroid \&optic disc morpho-metry. ${ }^{11}$ OCT images can be used to qualitative assessment of pathological changes in retina, which can also make quantitative measurements, in vivo. ${ }^{12,13}$ Spectral Domain OCT is being used to evaluate retinal vessel diameter in recent trends. ${ }^{14,15}$ OCT plays important role to be considered as good tool for screening, diagnosis \&treatment for assessment \& evaluation of diabetic retinopathy. ${ }^{11}$

The main purpose for conduction of this study was to determine whether diabetes affects the macular thickness, with the aim to compare central macular thickness in normal and diabetic patients without diabetic retinopathy.

\section{Materials and Methods}

Minimum age of respondents in present study was 30 years and maximum age was 55 years. A written informed consent was obtained from all the participants. Participants were divided into three groups: 1 . With diabetes mellitus more than 5 years 2 . With diabetes less than 5 years and 3 . Normal and healthy individuals.

The inclusion criteria in the diabetes group were age between 30 and 55 years, without microvascular or macrovascular complications of DM and with oral or subcutaneous treatment of hyperglycemia. Healthy control subjects did not have any diagnosed ocular disease, diabetes, or other systemic disease.

Subjects with cardiovascular pathology, renal failure, diabetic neuropathy or glycosylated hemoglobin (HbA1c) > $86 \mathrm{mmol} / \mathrm{mol}(10 \%)$, were excluded from the study. We also excluded eyes with diabetic retinopathy, previous laser Corresponding Author: Sumita Karandikar, Associate Professor, Dept. of Ophthalmology, DY. Patil Medical College, Mumbai, Maharashtra, India

Email: dr.sumitakarandikar@gmail.com http://doi.org/10.18231/j.ijceo.2019.092 
photocoagulation, history of ocular surgery, ocular diseases that could cause degeneration (glaucoma, uveitis or retinal disease including retinal vein occlusion and age related macular degeneration) and refractive error of more than 3.00 spherical diopters and 1.00 cylindrical diopters. Patients with blurred ocular media intraocular pressure $>21 \mathrm{mmHg}$ abnormal perimetry and inadequate pupil dilatation were excluded.

All the participants passed a screening examination that included a full medical history, physical examination, blood sampling (for glycosylated hemoglobin), best corrected visual acuity measurement, slit lamp biomicroscopy, IOP measurement.

Statistical analysis was done using SPSS 20.0 software. Descriptive statistical data were described as mean and categorical data and were presented as percentages. Total retinal thickness in every quadrant was recorded for the DM and healthy groups. The $\mathrm{P}$ value $<0.05$ was considered statistically significant.

\section{Results}

A total 101 participants were in the study out of which 51 were with diabetes and rest 50 were without diabetes. 25 had diabetes for less than 5 years duration and 26 had diabetes for more than 5 year duration. Comparison of central macular thickness in normal and diabetic patients without diabetic retinopathy was done by applying proper tests. 54 were female participants and 47 were male participants.

Table 1: Distribution according to HbA1C among patients

\begin{tabular}{|c|c|c|c|c|c|}
\hline HbAIC & Number & Mean & SD & Min & Max \\
\hline Diabetes $<5$ & 25 & 0.055 & 0.006 & 0.040 & 0.065 \\
\hline Diabetes > 5 & 26 & 0.069 & 0.007 & 0.056 & 0.080 \\
\hline Normal & 50 & 0.046 & 0.005 & 0.040 & 0.060 \\
\hline
\end{tabular}

Significant association was found $(\mathrm{P}<0.05)$. Mean HbA1C among patients with diabetes more than 5 years $(6.9 \pm 0.7 \%)$ was greater as compared to $\mathrm{HbA} 1 \mathrm{C}$ of those with diabetes less than 5 years $(5.5 \pm 0.6 \%)$ and normal cases $(4.6 \pm 0.5 \%)$

Table 2: Distribution of superior central macular thickness among patients

\begin{tabular}{|c|c|c|c|c|c|}
\hline Superior & Number & Mean & SD & Min & Max \\
\hline Diabetes $<5$ & 50 & 171.94 & 26.39 & 122.00 & 236.00 \\
\hline Diabetes $>5$ & 52 & 228.81 & 15.10 & 198.00 & 252.00 \\
\hline Normal & 100 & 121.32 & 14.60 & 80.00 & 200.00 \\
\hline
\end{tabular}

Significant association was found $(\mathrm{P}<0.05)$. Mean thickness of diabetic with duration less than 5 years was $171.94 \pm 26.3$ while those with diabetes more than 5 years was $238 \pm 15.10$. Mean superior quadrant thickness at the macula of normal patients was 121.32 \pm 14.69 . Thus diabetics with disease more than 5 years had more superior quadrant central macular thickness

Table 3: Distribution of inferior central macular thickness among patients

\begin{tabular}{|c|c|c|c|c|c|}
\hline Inferior & Number & Mean & SD & Min & Max \\
\hline Diabetes $<5$ & 50 & 161.64 & 32.82 & 83.00 & 215.00 \\
\hline Diabetes > 5 & 52 & 193.23 & 15.47 & 154.00 & 220.00 \\
\hline Normal & 100 & 101.55 & 20.37 & 60.00 & 143.00 \\
\hline
\end{tabular}

Significant association was found $(\mathrm{P}<0.05)$. Mean thickness of diabetic with duration less than 5 years was $161.94 \pm 32.8$ while those with diabetes more than 5 years was 193.23 \pm 15.47 . Mean inferior thickness of normal patients was 101.55 \pm 20.37 . Thus diabetics with disease more than 5 years had more inferior quadrant macular thickness

Table 4: Distribution of temporal central macular thickness among patients

\begin{tabular}{|c|c|c|c|c|c|}
\hline Temporal & Number & Mean & SD & Min & Max \\
\hline Diabetes < 5 & 50 & 169.78 & 35.08 & 69.00 & 210.00 \\
\hline Diabetes > 5 & 52 & 194.00 & 17.23 & 165.00 & 260.00 \\
\hline Normal & 100 & 150.19 & 36.97 & 69.00 & 240.00 \\
\hline
\end{tabular}

Significant association was found $(\mathrm{P}<0.05)$. Mean thickness of diabetic with duration less than 5 years was $169.78 \pm 35.08$ while those with diabetes more than 5 years was 194.00 \pm 17.23 . Mean temporal thickness of normal patients was 150.19 \pm 30.97 . Thus diabetics with disease more than 5 years had more temporal quadrant macular thickness 
Table 5: Distribution of nasal central macular thickness among patients

\begin{tabular}{|c|c|c|c|c|c|}
\hline Nasal & Number & Mean & SD & Min & Max \\
\hline Diabetes $<5$ & 50 & 172.66 & 25.39 & 120.00 & 205.00 \\
\hline Diabetes $>5$ & 52 & 202.04 & 27.13 & 156.00 & 260.00 \\
\hline Normal & 100 & 151.82 & 27.91 & 69.00 & 200.00 \\
\hline
\end{tabular}

Significant association was found $(\mathrm{P}<0.05)$. Mean thickness of diabetic with duration less than 5 years was $172.66 \pm 25.39$ while those with diabetes more than 5 years was 202.04 \pm 27.13 . Mean nasal thickness of normal patients was 151.82 \pm 27.91 . Thus diabetics with disease more than 5 years had more nasal quadrant macular thickness

Table 6: Distribution of foveal thickness among patients

\begin{tabular}{|c|c|c|c|c|c|}
\hline Fovea & Number & Mean & SD & Min & Max \\
\hline Diabetes $<5$ & 50 & 176.20 & 32.00 & 112.00 & 230.00 \\
\hline Diabetes $>5$ & 52 & 219.27 & 14.84 & 180.00 & 245.00 \\
\hline Normal & 100 & 123.13 & 17.16 & 90.00 & 206.00 \\
\hline
\end{tabular}

Significant association was found $(\mathrm{P}<0.05)$. Mean thickness of diabetic with duration less than 5 years was $176.32 \pm 32$ while those with diabetes more than 5 years was 219.27 \pm 14.84 . Mean foveal thickness of normal patients was $123.13 \pm 17.16$. Thus diabetics with disease more than 5 years had more foveal thickness.

\section{Discussion}

Timely diagnosis and intervention can prevent irreversible vision loss due to diabetic retinopathy. Various aetiological factors like hyperglycemia and changes in caliber of retinal vasculature have been postulated as responsible in determining the severity and progression of diabetic maculopathy.

In recent years various studies have established Optical Coherence Tomography (OCT) has proven to be an invaluable tool in diagnosis and management of diabetic maculopathy as it is quick, accurate, non-invasive and easily reproducible. ${ }^{16-17}$ OCT can detect macular oedema, vitreomacular traction, taught posterior hyaloid which helps in early diagnosis and appropriate intervention in cases of diabetic maculopathy.

Central Macular Thickness (CMT) is known to increase in diabetic patients due to increase in vascular permeability. Multiple studies have measured central macular thickness in diabetic patients but the results are variable with no clear correlation between CMT and duration of diasease or vision. In this study, we investigated if, Central Macular Thickness measured with OCT can detect pre-clinical disease and thus identify the subset of patients who are at risk to develop clinical maculopathy. Glycosylated Hemoglobin is a consistent and predictable marker for long term control of blood sugar level in diabetic patients. Other studies have shown relationship between $\mathrm{HbAlc}$ levels and macular volume as well as diabetic macular edema. ${ }^{18-20}$ In our study, comparison of CMT in diabetic patients with normal HbAlc level to those with elevated levels of $\mathrm{HbA} 1 \mathrm{c}$ revealed a statistically significant increase in the latter group possibly indicating the role of uncontrolled hyperglycemia in vascular deregulation leading to increased permeability.
Demir et al, in their study did not find significant association between increased macular thickness and duration of diabetes. ${ }^{1,2}$ They also did not find increased CMT with increased levels of HbA1c, contrary to our study. Quadrant (Nasal/ Temporal/ Superior/ Inferior) to quadrant comparison of macular thickness also showed increase in patients with diabetes more than 5 years those with the disease for less than 5 years which in turn was more than the control population. The increase in thickness was statistically significant ( $\mathrm{T}$ Test) in each instance. This corroborates the hypothesis that duration of disease is an important factor for onset of diabetic retinopathy. As none of these patients demonstrated clinically evident retinopathy, this finding shows that serial measurements of CMT in diabetic patients is an important investigation which can indicate the trend towards clinical retinopathy if progressive increase in thickness is noted.

Further studies with a larger sample size are needed to analyze these results as well as to investigate to correlation between CMT and other parameters like visual acuity and vascular permeability in pre-clinical retinopathy.

\section{Conclusion}

CMT, as measured on OCT is an effective and non-invasive investigation to monitor progress of retinopathy in diabetic patients and can help predict onset of clinical retinopathy. Additional studies can further establish the relationship of CMT measurement to other key parameters in the assessment of diabetic retinopathy.

\section{Source of Funding: None.}

\section{Conflict of Interest: None.}

\section{References}

1. Demir M, Dirim B, Acar Z, Yilmaz M, Sendul Y. Central macular thickness in patients with type 2 diabetes mellitus without clinical retinopathy. J Ophthalmol. 2013;2013:767931.

2. Demir M, Oba E, Dirim B, Ozdal E, Can E. Central macular thickness in patients with type 2 diabetes mellitus without clinical retinopathy. BMC Ophthalmol. 2013;13:11

3. W.H.O. Global report on Diabetes. 2016. 
4. Guariguata L, Whiting DR, Hambleton I, Beagley J, Linnenkamp U, Shaw JE et al. Global estimates of diabetes prevalence for 2013 and projections for 2035. Diabetes Res Clin Pract. 2014;103(2):137-49.

5. Cheung N, Mitchell P, Wong TY. Diabetic retinopathy. Lancet. 2010; 376(9735):124-36.

6. Congdon N, O'Colmain B, Klaver CC, Causes and prevalence of visual impairment among adults in the United States. Arch Ophthalmol 2004;122(4):477-85.

7. Klein R, Klein BE, Moss SE, The Wisconsin epidemiologic study of diabetic retinopathy. XV. The long term incidence of macular edema. Ophthalmol 1995;102(1):7-16.

8. Simo R. Neurodegeneration as an early event in diabetic retinopathy. Endocrinologia y nutricion: organo de la Sociedad Espanola de Endocrinologia y Nutricion. 2011;58(5):211-3.

9. Simo R, Hernandez C. Neurodegeneration in the diabetic eye: new insights and therapeutic perspectives. Trends Endocrinol Metabo. 2014; 25(1):23-33.

10. Stefanescu AM, Gradinaru SL, Tugui A, Ciuluvica R. Cefaleea-abordare din punct de vedere oftalmologic. Oftalmologia. 2011; 55(3):30-7.

11. Massin P, Girach A, Erginay A, Gaudric A. Optical coherence tomography: a key to the future management of patients with diabetic macular oedema. Acta Ophthalmol Scand. 2006;84(4):466-74.

12. Cabrera Fernandez D, Salinas HM, Puliafito CA. Automated detection of retinal layer structures on optical coherence tomography images. Optics Express. 2005;13(25):10200-16.

13. Stana D, Iancu R, Leasu C, Popescu V, Dumitrescu A, Gradinaru $S$ et al. The role of Spectral Domain Optical Coherence Tomography in monitoring uncontrolled hypertensive type 2 diabetic patients. J Med Life. 2014;7(4):65-7.

14. Zhu TP, Tong YH, Zhan HJ, Ma J. Update on retinal vessel structure measurement with spectral-domain optical coherence tomography. Microvascular Res. 2014;(7-14).
15. Couper DJ, Klein R, Hubbard LD, Wong TY, Sorlie PD, Cooper LS et al. Reliability of retinal photography in the assessment of retinal microvascular characteristics: the Atherosclerosis Risk in Communities Study. Am J Ophthalmol. 2002;133(1):78-88.

16. 16. Moreira RO, Trujillo FR, Meirelles RM, Ellinger VC, Zagury L: Use of optical coherence tomography (OCT) and indirect ophthalmoscopy in the diagnosis of macular edema in diabetic patients. Int Ophthalmol. 2001;24: 331-6.

17. Schneeberg AE, Göbel W: Diagnosis and follow-up of nondiabetic macular edema with optical coherence tomography (OCT). Ophthalmol. 2003;100: 960-966. 10.1007/s00347-0030822-2.

18. Yeung L, Sun CC, Ku WC, Chuang LH, Chen CH, Huang BY et al: Associations between chronic glycosylated haemoglobin (HbAlc) level and macular volume in diabetes patients without macular oedema. Acta Ophthalmol. 2010, 88: 753-758. 10.1111/j.1755-3768.2009.01711.x.

19. Chou TH, Wu PC, Kuo JZ, Lai CH, Kuo CN: Relationship of diabetic macular oedema with glycosylated haemoglobin. Eye (Lond). 2009, 23: 1360-1363. 10.1038/eye.2008.279.

20. Rosenstock J, Friberg T, Raskin P: Effect of glycemic control on microvascular complications in patients with type I diabetes mellitus. Am J Med. 1986;81:1012-1018. 10.1016/00029343(86)90398-0.

How to cite this article: Tadwalkar A, Karandikar S, Sharma P. Comparison of central macular thickness by optical coherence tomography (OCT) in normal and diabetic patients without diabetic retinopathy. Indian J Clin Exp Ophthalmol. 2019;5(3):386-9. 